\title{
Genotoxic effects of albendazole in patients medicated for cystic echinococcosis
}

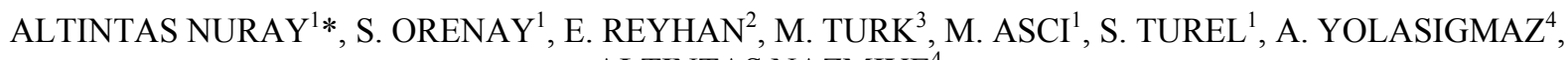 \\ ALTINTAS NAZMIYE ${ }^{4}$
}

${ }^{1}$ Celal Bayar University, School of Medicine, Dept.of Medical Biology and Genetics, Manisa, Turkey, E-mail: nuray.altintas@bayar.edu.tr; ${ }^{2}$ Atatürk Research and Training Hospital, Dept.of General Surgery, İzmir, Turkey;

${ }^{3}$ Atatürk Research and Training Hospital, Dept.of Microbiology, İzmir, Turkey; ${ }^{4}$ Ege University, School of Medicine, Dept. of Parasitology, İzmir, Turkey

\begin{abstract}
Summary
Cystic echinococcosis (CE) due to Echinococcus granulosus is one of the most important helminthic diseases in Turkey where it constitutes a public health and economic problems. Its mean annual incidence in humans is 4.4/100 000 and the prevalence of the tapeworm agent in domestic animals ranges from 11.2 to $50.7 \%$. Since 1980 s, albendazole has been used for treatment of the disease, and this benzimidazole drug has been considered to be of relatively low toxicity. However, prolonged albendazole therapy of CE became to be a common practice, and data on possible genotoxic effects of the medication in humans are lacking. This study has concerned 17 women and 11 men, in total 28 patients with liver cystic hydatid complaints, who were administered albendazole $(15 \mathrm{mg} / \mathrm{kg})$ preoperatively $(2$ weeks) and postoperatively (6 months). Genotoxic effects of albendazole were searched using Sister Chromatid Exchange (SCE), mitotic index (MI) and chromosomal aberations (CAs) methods, comparing lymphocyte chromosomes of treated patients and a control group of healthy individuals. The results indicated a significant increase of SCE frequencies and decrease of MI in the treated group (p $<0.001)$. Regarding CAs, any difference between the groups was not determined.
\end{abstract}

Key words: cystic echinococcosis; albendazole; genotoxicity; Sister Chromatid Exchange

\section{Introduction}

Many people are occupationally exposed to various biohazardous agents, including radiation, dust, fibers, fumes, organic and inorganic chemicals. Genetic biomonitoring of human populations exposed to potential mutagens/carcinogens can be performed using different genetic markers. Significant increase in Sister Chromatid Exchange (SCE) frequencies has been reported in studies of the human population who are exposed to genotoxic agents and represents one of the most extensively used early markers of DNA damage or epigenetic changes. SCE is the exchange of homologous stretches of DNA sequence between sister chromatids, it occurs normally in cells during mitotic cell division but an impact of genotoxic agents increases the rate of SCE (Zhang et al., 1991; Verma \& Babu, 1995; Albertini, 2000; Hagmar et al., 2001).

Cystic echinococcosis (CE) due to Echinococcus granulosus is one of the most important helminthic diseases in Turkey, where it constitutes public health and economic problems. Its mean annual incidence in humans is 4.4/100 000 and the prevalence of the tapeworm in domestic animals ranges from 11.2 to $50.7 \%$ (Altintas, 2003). Since 1980 s, treatment of CE with albendazole was well documented in over two thousand patients and this benzimidazole drug has been considered to have low toxicity (Von Siner, 1990; Wen et al., 1994; Ammann \& Eckert, 1995; Horton, 1997; Pawlowski et al., 2002). Chemotherapy, representing non-invasive treatment, could be used on patients of any age, although there is little experience with children younger than age 6 years. Moreover, this therapy is less limited by the patients' status (except pregnancy) than surgery. Unfortunately, potential risks of benzimidazoles include embryotoxicity and teratogenicity which, however, could only been observed in laboratory animals during early stages of pregnancy (Pawlowski et al., 2002). Recently, prolonged albendazole therapy of CE became common practice but sufficient data on possible genotoxic effects of the medication are lacking. Actually, an albendazole administration $(10-15 \mathrm{mg} / \mathrm{kg}) 2-4$ weeks before the operation and a long-termed post-operative oral treatment are now recommended. Monitoring of liver enzyme levels is advised during this therapy (Davis et al., 1986; 
Lacey, 1990; Horton, 1997; Pawlowski et al., 2002; Opatrny et al., 2005). However, little information exists about genotoxic effects of albendazole in humans.

The aim of this study was to investigate and evaluate potential genotoxicity caused by the exposure to albendazole by measuring Sister Chromatid Exchange (SCE), mitotic index (MI) and chromosomal aberations (CAs) in the peripheral lymphocytes of cystic hydatid patients, because no such data have been published to date.

\section{Materials and Methods}

\section{Patients}

This study included 28 patients (17 women and 11 men), suffering from liver cystic hydatid disease, who had been administered albendazole $(15 \mathrm{mg} / \mathrm{kg}, 2$ weeks before and 6 months after the operation). The control group comprised 28 healthy persons matched with respect to age, sex, smoking habits, drinking habits, and social status to patients from the experimental group. The mean age was 41 (range 15 - 72). Blood samples of the patients were collected at the end of the albendazole treatment. All the blood collections were made in disposable pre-sterilized heparinized syringes and transferred to laboratory for lymphocyte cultures.

Human Lymphocyte Culture and SCE, MI and CAs Assays Short-term lymphocyte cultures were prepared from heparinized blood (heparin $500 \mathrm{IU} / \mathrm{ml}$ without preservative) according to the method of Yadav and Seth (1998), with slight modifications published by Moorhead et al. (1960). Blood (0.5 ml) was added to $5 \mathrm{ml}$ RPMI 1640 medium containing $20 \%$ fetal calf serum, $100 \mathrm{U} / \mathrm{ml}$ penicillin, $100 \mu \mathrm{g} / \mathrm{ml}$ streptomycin, and $0.1 \mathrm{ml}$ phytohemagglutinin (Sigma, St. Louis, MO). Colchicine $(10 \mu \mathrm{g} / \mathrm{ml})$ was added to the culture $2 \mathrm{hr}$ before harvesting. The final concentration of colchicine was $100 \mu \mathrm{l}$.

Lymphocytes were harvested after $72 \mathrm{hr}$ and slides were air dried and stained with $4 \%$ Giemsa. (Perry \& Wolff, 1974). As many as 100 good metaphases (well -spread metaphases showing 46 chromosomes of proper morphology) per individual were screened for CA. For MI 5000 cells per individual were counted from Giemsa stained slides. MI was calculated by using the formula: number of dividing cells: total number of cells scored x 100 .

To determine SCEs, 5-bromodeoxyuridine $(10 \mu \mathrm{g} / \mathrm{ml} / \mathrm{cul}-$ ture; Sigma Aldrich) was added $24 \mathrm{hr}$ after preparing cultures. The cells on slides were stained directly in excess solution of Hoechst $33258\left(50 \mu \mathrm{g} / \mathrm{ml}\right.$ in $\mathrm{H}_{2} \mathrm{O}$; Sigma $)$. The slides were exposed to long-wave UV light of about $320-$ $400 \mathrm{~mm}$ intensity (30 minutes), then were rinsed with water and incubated for $15-30 \mathrm{~min}$ in $2 \mathrm{X} \mathrm{SSC}$ at $65^{\circ} \mathrm{C}$; and after another water rinsing they were stained with $2-3$ $\%$ Giemsa in phosphate buffer ( $\mathrm{pH}$ 6.8). For calculating the frequency of SCEs per cell, 25 metaphases per individual were analyzed as per international practice (Lindkov et al., 1984; Yadav \& Seth, 1998; Yadav \& Chadha, 2002). The SCE frequency was calculated separately for each morpho- logical category of human chromosomes, marked as A - G ( $C$ category includes the sex chromosome $X$ and $G$ category includes the Y, see Tab. 1, Fig. 2). For calculation of MI and CAs, 5,000 cells were scanned from Giemsa-stained subject slides.

The samples were analyzed blindly by two observers to remove possible laboratory scoring bias. For statistical analysis of differences between groups the Mann-Whitney U test was applied. Data used for the analysis were transformed by ArcSine transformation (Zar, 1999).

Table 1. Comparison of SCE frequency per cell (\%) in chromosome categories in 28 treated and 28 control persons.

\begin{tabular}{lccc}
\hline \multirow{2}{*}{$\begin{array}{l}\text { Chromosome } \\
\text { category }\end{array}$} & Treated group & & Control group \\
\cline { 2 - 2 } A & Average \pm S.D. & & Average \pm S.D. \\
\hline B & $39.17 \pm 4.11$ & & $3.03 \pm 2.26$ \\
$\mathrm{C}-\mathrm{X}$ & $70.03 \pm 3.04$ & & $4.46 \pm 1.80 \pm 1.20$ \\
$\mathrm{D}$ & $30.46 \pm 3.58$ & & $0.50 \pm 0.50$ \\
$\mathrm{E}$ & $34.67 \pm 3.51$ & & $1.89 \pm 0.87$ \\
$\mathrm{~F}$ & $35.53 \pm 3.09$ & & $1.57 \pm 0.83$ \\
$\mathrm{G}-\mathrm{Y}$ & $40.14 \pm 1.45$ & & $1.60 \pm 0.62$ \\
\hline
\end{tabular}

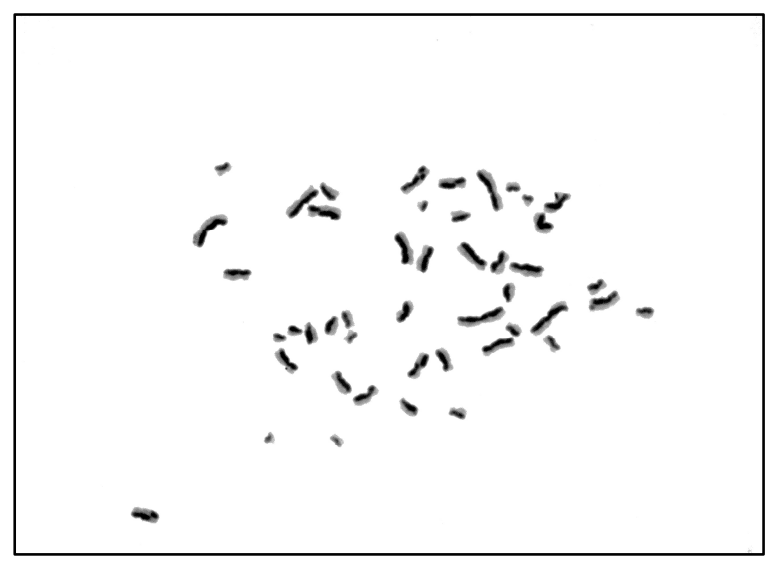

Fig. 1. Metaphase sample of the experimental group

\section{Results}

On account of chromosomal aberations (CAs) between the group of liver $\mathrm{CE}$ patients medicated with albendazole and the control group, there were no significant differences. On the other hand, lower values of mitotic index (MI) were observed in the treated group (0.030) compared with the control (0.035) (Table 2).

A comparison of SCE in the experimental and control groups revealed a statistically significant increase of SCE frequency in albendazole medicated patients $(\mathrm{p}<0.001)$. The highest SCE frequency was detected in chromosomes of $\mathrm{C}-\mathrm{X}$ type and the lowest in 3D-type (three D-group chromosome) (Table 1). Figures $1-3$ show the chromosome breakages detected in representatives of the experimental as well as the control groups. 
Table 2. Data on mitotic frequency in 28 experimental and 28 control

\begin{tabular}{lccc}
\multicolumn{2}{c}{ persons } & \\
\hline & Treated group & & Control group \\
\cline { 2 - 2 } & Average \pm S.D. & & Average \pm S.D. \\
\hline No. of observed cells & $2170.0 \pm 155.1$ & & $3110.4 \pm 353.2$ \\
No. of mitotic cells & $65.4 \pm 10.6$ & & $108.4 \pm 18.2$
\end{tabular}

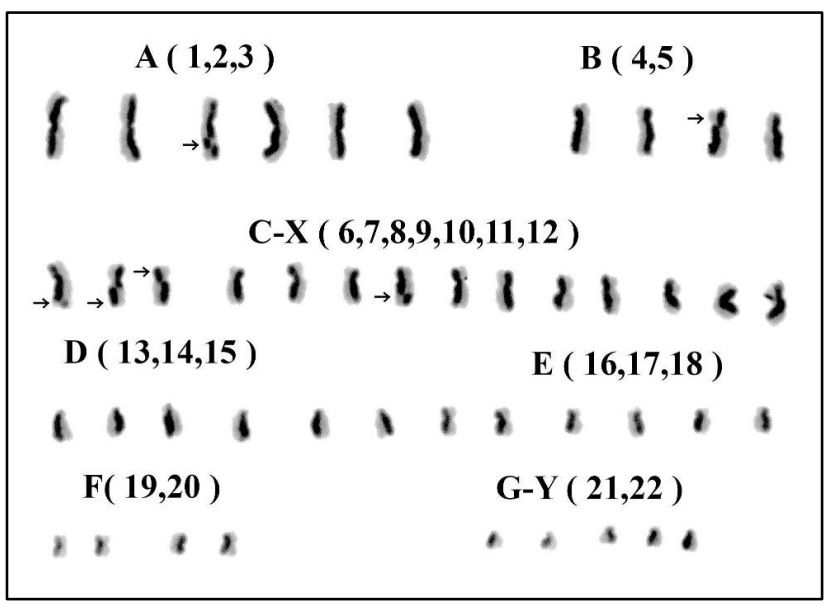

Fig. 2. Karyograme of the experimental group

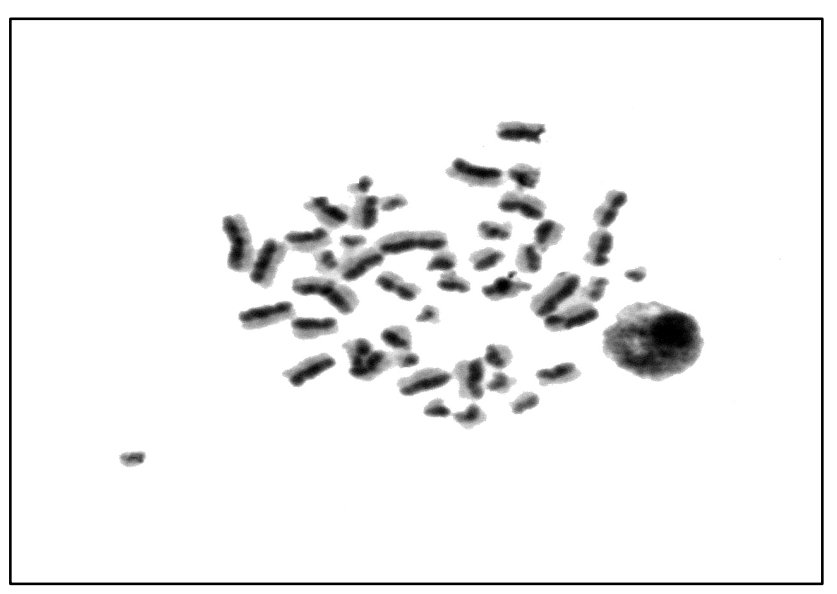

Fig. 3. Metaphase sample of the control group

\section{Discussion}

Cytogenetic assays have been used since the early 1960s to evaluate the exposure of patients to potentially mutagenic and carcinogenic agents (Chai et al., 2004). SCE, MI and CA analyses were used in many such studies. In order to determine agent-related effects, it is very important to collect samples from a control group that is matched as closely as possible to the experimental group in all regards except for the exposure being evaluated (Albertini et al., 2000). In our study, we had chosen individuals for both the experimental and control group who were non-smokers and did not use alcohol.
SCE analysis has been considered a sensitive method for detecting genotoxic effects of chemical substances, i.e. DNA damage (mutagenic effect) or, in other cases, targeting DNA repair mechanism or influencing the cell cycle (Tucker \& Preston, 1996). Thus, a positive SCE response does not necessarily mean that a tested compound is a mutagenic carcinogen, however, a potential genotoxic effect could be pre-screened using SCE technique in combination with data on mitotic index and chromosomal aberations. However, a conclusive examination of carcinogenicity of a chemical would require additional tests (Perry \& Evans, 1975; Stetka \& Wollf; 1976). In human lymphocytes, the SCE frequency is usually very steady, and does not vary with age or sex. Thus using a method of SCE detection for exploring a toxicity and harm caused by albendazole is of great importance (Yadav \& Seth, 1998).

Albendazole is a drug used in treatment of helminthiases including cystic hydatid disease. When this drug is metabolized by host and parasite cells, it inhibits the formation of microtubules during metaphase and prevents cell prolixferation. Thus albendazole affects hosts and parasite cells alike. Related to this, leukopenia, liver disfunction and alopecia was reported in patients with albendazole administration, however, the number of studies about the genotoxic and teratogenic effects of albendazole is still not sufficient (Teggi et al., 1993; Menghebat et al., 2004; Altintas et al., 2005). Whittaker and Faustman $(1991,1992)$ reported that benzimidazoles, including albendazole, should be considered potential developmental toxicants on cultures of differrentiating rodent embryonic cells. Mutagenic and carcinogenic potential of albendazole was studied by Frohberg (1989) and Mantovani (1992). Otubanjo and Mosuro (2001), using the murine sperm-head abnormality test, reported that the drug might not be mutagenic. As we mentioned above, a proper testing of the mutagenicity and carcinogenicity, i.e. direct damage of DNA by alkylation compounds, would require further tests.

This study, however, has shown noticeably increased frequencies of SCE in various morphological categories of chromosomes. These findings support the strong genotoxic effect of the drug that might be related to the influenced cell cycle. Similarly, Yadav and Seth (1998) found an increase of SCE most frequently in DG (one D-group chromosome and one G-group chromosome) chromosomes association and most rarely in $3 \mathrm{D}$ (three D-group chromosomes) association during their study of a impact of polycyclic hydrocarbon to coal tar workers. Our findings support their 3D-type findings. But high SCE frequency in C$\mathrm{X}$ type chromosomes in our study does not confirm findings on high SCE frequency in DG type chromosomes of Yadav and Seth (1998).

Our results demontrated the decrease of MI in treated patients compared with the control group, which is in a good accord in vitro studies associated with genotoxic agents tested on human peripheral lymphocytes (Celik \& Aras, 2006; Aydemir et al., 2005; Rencuzogullari et al., 2001, 2004; Rupa et al.,1989; Meng et al., 1994).

The present study confirmed a link between the increasing 
of SCE frequencies in cystic hydatid disease patients who were treated long-term by albendazole. As there have been no reports on the potential genotoxic, mutagenic or carcinogenic effects of albendazole treatment in the literature, this study has shown the apparent genotoxic effects and would suggest follow-up analyses. The authors suggest a serial monitoring of the SCE should be performed in addition to the existing recommendation of monitoring of liver enzyme levels in cystic hydatid patients who had been administered albendazole for a long time (especially if radical surgery is impossible or for prevention of secondary echinococcosis). The increase of SCE and decreasing MI in peripheral blood lymphocytes of these patients may indicate that this anthelminthic drug is a genotoxic agent and there is not excluded DNA and chromosome damage. However, there is a need to confirm the present results on basis of larger study populations and employing other biomarkers of genotoxicity.

\section{References}

AlBertini, R. J. (2000): Sister chromatid exchanges (SCEs) in lymphocytes. Mutat. Res., 463: 165 - 72

Albertini, R. J., Anderson, D., Douglas, G. R., Hagmar, L., Hemminki, K., Merlo, F., Natarajan, A. T., Norppa, H., Shuker, D. E., Tice, R., Waters, M. D., AITIO, A. (2000): IPCS guidelines for the monitoring of genotoxic effects of carcinogens in humans. International Programme on Chemical Safety. Mutat. Res., 463: 111 72

Altintas, N. (2003): Past to present: echinococcosis in Turkey. (Special Issue: New Dimensions in Hydatidology in the New Milennium. Eds. Altıntaş N, Peter Schantz) Acta Trop., 85: $105-112$

Altintas, N., Orenay, S., Asci, M., Turk, M., Reyhan, E., Yolasigmaz, A., Altintas, N. (2005): Sister Chromatid Exchange (SCE) study in patients with liver cystic hydatid disease who have been administered albendazole: Preliminary study. Turkiye Parasitol. Derg., 29: 235 - 237 AMMANN, R., ECKERT, J. (1995): Clinical diagnosis and treatment of echinococcosis in humans. In THOMPSON R.C.A. and LYMBERY A. J. (Eds): Echinococcus and Hydatid Disease, p. $411-451$

Aydemir, N., Celiker, S., Bilaloglu, R. (2005): In vitro genotoxic effects of anticancer drug gemcitabine in human lymphocytes. Mutat. Res., 582: $35-41$

Celik, A., ARAS, ATES, N. (2006): The frequency of sister chromatid exchanges in cultured human peripheral blood lymphocyte treated with metronidazole in vitro. Drug Chem Toxicol; 29: 85 - 94

Chai, J. M., Wei, J., DeyU, S., Bin, L., JincaO, S., Chen, F., Xiong, L., Yiding, M., Xiuling, W., Guliber, D., Yanchun, W., Fanghua, G., Shuhua, X. (2004): Observations on clinical efficacy of albendazole emulsion in 264 cases of hepatic cystic echinococcosis. Parasitol. Int., 53: $3-10$

Davis, A., Pawlowski, Z. S., DiXon, H. (1986): Multicentre clinical trials of benzimidazole carbamates in human echinococcosis. Bull WHO, 64: 383 - 388

FROHBERG, H. (1989): The toxicological profile of praziquantel in comparison to other anthelminthic drugs. Acta Leiden., 57: $201-215$

Hagmar, L., Strönberg, U., Tinnerberg, H., Mikoczy, Z. (2001): The usefulness of cytogenetic biomarkers as intermediate endpoints in carcinogenesis. Int. J. Hyg. Environ. Health, 204: $43-7$

HORTON, R. (1997): Albendazole in treatment of human cyctic echinococcosis: 12 years of experience. Acta Trop., 64: $79-93$

LACEY, E. (1990): Mode of action benzimidazoles. Parasitology Today, 6: $112-115$

LindKov, R., Wulf, H. C., Wantzin, G. L., Niebuhr, E. (1984): Sister chromatid Exchange in patients treated with methotrexate for psoriasis. J. Invest. Dermatol., 82: 458 459

MANTOVANI, A. (1992): The role of multigeneration studies in safety assessment of residues of veterinary drugs and additives. Ann. Ist. Super Sanita, 28: 429 - 35

MENG, Z., ZHANG, L. (1994): [Chromosomal aberrations, sister chromatid exchanges and micronuclei induced in human lymphocytes by sodium bisulfite (sulfur dioxide)] Yi Chuan Xue Bao, 21: 1 - 6

Menghebat, J, (Junjie) C.,Wei, J., Deyu, S., Bin, L., JincaO, S., Chen, F., Xiong, L., Yiding, M., Xiuling, W., Guliber, D., Yanchun, W., Fanghua, G., Shuhua, X. (2004): Observations on clinical efficacy of albendazole emulsion in 264 cases of hepatic cystic echinococcosis. Parasitol. Int., 53: 3 - 10

Moorhead, P. S., Nowell, P. C., Millman, W. J., BAtTIPS, W. J., HunDERFORD, D. A. (1960): Chromosome preparation of leucocytes cultured from human peripheral blood. Exp. Cell. Res., 20: 613-616

Opatrny, L., Prichard, R., Snell, L., Maclean, J. D. (2005): Death related to albendazole-induced pancytopenia: case report and review. Am. J. Trop. Med. Hyg., $291-$ 294

Otubanjo, O. A., Mosuro, A. A. (2001): An in vivo evaluation of induction of abnormal sperm morphology by some anthelmintic drugs in mice. Mutat Res., 497: 131 138

Pawlowski, Z. S., Eckert, J., Vuitton, D. A., Ammann, R. W., Kern, P., Craig, P. S., Dar, K. F., De Rosa, F., Filice, C., Gottstein, B., Grimm, F., MacPherson, C. N. L, SATo, N., Todorov, T., Uchino, J., VOn Sinner, W., WEN, H. (2002): Echinococcosis in humans: clinical aspects, diagnosis and treatment. In ECKERT J., GEMMELL, M.A., Meslin, F.-X., PAWLOWSKI, Z. S. (Eds.): WHO/OIE Manual on Echinococcosis in Humans and Animals: a Public Health Problem of Global Concern, p. $47-58$

Perry, P., Evans, H. J. (1975): Cytological detection of mutagen-carcinogenexposure by sister chromatid exchange. Nature, 258: $121-125$

Perry, P., Wolf, S. (1974): New giemsa method for the differential staining of sister chromatids. Nature, 251: 156 $-158$

Rencuzogullari, E., Ila, H. B., Kayraldiz, A., Ar- 
Slan, M., Diler, S. B., TopaKtas, M. (2004): Genotoxic effects of potassium bromate on human peripheral lymphocytes in vitro. Genetika, 40:1571 - 1575

Rencuzogullari, E., Ila, H. B., Kayraldiz, A., TopaKTAS, M. (2001): Chromosome aberrations and sister chromatid exchanges in cultured human lymphocytes treated with sodium metabisulfite, a food preservative. Mutat. Res., 490: 107 - 12

RuPA, D. S., REDDY, P. P., REDDI, O. S. (1989): Genotoxic effect of benzene hexachloride in cultured human lymphocytes. Hum. Genet., 83: $271-273$

StetKa, D. G., Wollf, S. (1976): Sister chromatid Exchange as an assay for genetic damage induced by mutagen-carcinogens. I. In vivo test for compounds requiring metabolic activation. Mutat. Res., 41: $333-342$

Teggi, A., Lastilla, M. G., De Rosa, F. (1993): Therapy of human hydatid disease with mebendazole and albendazole. Antimicrobial Agents and Chemotherapy, 37: 1679 1684

Tucker, J. D., Preston, R. J. (1996): Chromosome aberrations, micronuclei, aneuploidy, sister chromatid exchanges, and cancer risk assessment. Mutat. Res., 365: 147 159

VERMA, R. S., BABU, A. (1995): Specialized tecniques, sister chromatid diferentition. In: Human chromosomes principles and tecniques. Mc Graw-Hill: Newyork, 143 - 52

VON SINER, W. (1990): Successful treatment of disse- minated hydatid disease using albendazole monitored by CT. Eur. J. Radiol., 11: $232-233$

Wen, H., ZOU, P. F., YANG, W. G., LU, J., WANG, Y. H., AHANG, J. H., NEW, R. R., CRAIJ, P. S. (1994): Albendazole chemotherapy for human cystic and alveolar echinococcosis in North-western hina. Trans. Roy. Soc. Trop. Med. Hyg., 88: $40-343$

WhitTaker, S. G., Faustman, E. M. (1991): Effects of albendazole and albendazole sulfoxide on cultures of differentiating rodent embryonic cells. Toxicol Appl Pharmacol., 109: 73 - 84

Whittaker, S. G., Faustman, E. M. (1992): Effects of benzimidazole analogs on cultures of differentiating rodent embryonic cells. Toxicol. Appl. Pharmacol., 113: $144-$ 151

YADAV, J. S., SETH, N. (1998): Effect of NOx on the somatic chromosomes of Goldsmiths. Environ. Health Perspect, 106: 643 - 647

YADAV, J. S., ChadHa, P. (2002): Genotoxic studies in Pan Masala chewers: a high cancer risk group. Int. J. Hum. Genet., 2: $107-112$

Zhang, Z., YANG, L., ZHANG, Q., CAO, X. (1991): Studies on the utilization of a plant SCE test in detecting potential mutagenic agents. Mutat Res., 261: $69-73$

ZAR, J. H. (1999): Biostatistical Analysis. Fourth Edition. Prentice Hall, Upper Saddle River, New Jersey, USA, pp. 663 